\title{
Incidence and Risk Factors of Low Birth Weight Among Babies Delivered at Tertiary Level Teaching Hospital in Nepal
}

\author{
Pawana Kayastha and Sunil Raja Manandhar
}

Department of Paediatrics, Kathmandu Medical College Teaching Hospital, Sinamangal, Kathmandu, Nepal

\begin{abstract}
Introduction: Low birth weight is directly related to both immediate and long term development and wellbeing of a person. There are numerous maternal and foetal factors contributing to low birth weight. The mortality and morbidity of low birth weight can be reduced if the maternal risk factors are detected early and managed by simple techniques.

Methods: 207 low birth weight live newborn babies regardless of gestational age born in a tertiary level teaching institute from September 2015 to September 2016 were enrolled as cases and same number of normal birth weight babies (i.e. 2.5 to $4 \mathrm{kgs}$ ) as control. Information was obtained directly from mothers using pretested structured questionnaire and was analysed using SPSS version 20.

Results: The incidence of low birth weight was found to be $9.8 \%$. Mean weight of low birth weight babies was $1.98 \mathrm{~kg}$ and mean gestational age was 37.34 weeks. Among low birth wight babies, 47.8\% were preterm and $52.2 \%$ were term. Out of 119 small for gestational age babies, the frequency of symmetrical small for gestational age was $45.3 \%$ and asymmetrical small for gestational age was $54.6 \%$. There was significant association of low birth weight with multiple maternal factors like maternal age, education, weight, height, weight gain during pregnancy, ANC visits, parity, antepartum haemorrhage, previous abortion/low birth weight, birth spacing, tobacco/alcohol intake and haemoglobin.

Conclusions: Prevalence of low birth weight is likely to be far higher than figure in isolated rural settings of our country. Contribution of SGA is higher than Appropriate for Gestational Age which brings us to a larger burden of long term morbidity and mortality. Various maternal factors are responsible for birth of low birth weight babies.

Key words: low birth weight; maternal risk factors; morbidity; mortality
\end{abstract}

Correspondence: Pawana Kayastha, Department of Paediatrics, Kathmandu Medical College Teaching Hospital, Sinamangal, Kathmandu, Nepal.E-mail: paw_ana@hotmail.com

DOI: http://dx.doi.org/10.3126/mjsbh.v18i2.22202

Submitted on: 2019-01-01

Accepted on: 2019-06-15

This work is licensed under creative common license:

http://creativecommons.org/licenses/by-nc-nd/4.0/ C MJSBH 2019 


\section{INTRODUCTION}

Low birth weight (LBW) is defined as a weight at birth less than 2,500 grams irrespective of gestational age. They are broadly categorised under two major categories; one is neonates who are born Small for Gestational Age (SGA) as a result of factors affecting the rate of intrauterine growth and second is neonates whose birth weight is appropriate for their gestational age (AGA) but who are LBW because they are born prematurely, due to factors affecting the duration of gestation. Birth weight is a strong indicator of maternal health care and nutritional status as well as newborn's chances for survival, growth, long-term health and psychosocial development. LBW is the leading indirect cause of neonatal mortality and also an established important risk factor for neonatal morbidity.' Recent studies have found that LBW also increases the risk for noncommunicable diseases such as diabetes and cardiovascular disease later in life. Overall, it is estimated that $15 \%$ to $20 \%$ of all births worldwide are LBW, representing more than 20 million births a year. ${ }^{6}$ South Asia has the highest incidence of low birth weight and accounts for more than half of the world's LBW babies. ${ }^{3}$ In 2011, Sri Lanka, Nepal, Bangladesh and Pakistan had the highest number of low birth weight infants in the Asia Pacific region. ${ }^{3}$ DHS data of 2011 shows the percentage of babies with low birth weight in Nepal to be $16 \%$. Several foetal, maternal and environmental factors contribute to birth weight. ${ }^{6}$ The present study is proposed to record the incidence of LBW in a tertiary level teaching hospital and to explore the maternal risk factors associated with LBW; such a study will be beneficial to identify and carry out effective measures to reduce the burden of this problem.

\section{METHODS}

This is a cross-sectional prospective analytical study carried out at a tertiary level teaching hospital in Kathmandu, Nepal. 207 single live LBW (i.e. birth weight of $<2500 \mathrm{gm}$ ) irrespective of gestational age, delivered via normal or instrumental or cesarean section during the study period were taken as cases and same number of normal birth weight babies (i.e. 2.5 to $4 \mathrm{~kg}$ ) irrespective of gestational age were taken as control. Babies who were multiple births, still birth, with congenital malformations, chromosomal anomalies, and haemolytic disease of newborn and those refusing to give consent were excluded from the study. Informed consent from participants was taken prior to the data collection. Each questionnaire was completed and birth weight was taken within 24 hours of birth. Maternal nutritional status was assessed by postpartum weight and height. Information about maternal haemoglobin, gestational age and morbidity during pregnancy and other required data were taken from the medical records. The analysis was done using Social Sciences (SPSS) software version 20. Simple descriptive analysis, and multiple variables were analysed by chi-square test to see the statistical significance taking $\mathrm{p}$ value $<0.05$ as statistical significant value. Institutional ethical clearance was obtained.

\section{RESULTS}

The incidence of low birth weight was found to be $9.8 \%$ in our study. The birth weight of newborn with LBW ranged from $0.76 \mathrm{~kg}$ to $2.48 \mathrm{~kg}$, and mean birth weight was $1.98 \mathrm{~kg}$. Gestation age of the newborn with LBW was 37.34. Among LBW $57.5 \%(\mathrm{n}=119)$ were SGA and $42.5 \%(\mathrm{n}=88)$ were AGA. Out of total SGAs the frequency of symmetrical SGA was $45.3 \%(\mathrm{n}=54)$ and asymmetrical SGA $54.6 \%(n=65)$. Among the studied LBW babies, 51.2\% $(\mathrm{n}=106)$ were female and $48.7 \%(\mathrm{n}=101)$ were males. Whereas in control group $55.87 \%(\mathrm{n}=114)$ male and female were $44.92 \%(n=93)$. However the difference was statistically not significant $(p=0.201)$.

Teenager and elderly mothers (more than 35years) were observed more with LBW babies than in mothers with normal birth weight babies. This differences in case and control group came out to be statistically significant $(p=0.000) .9 .2 \%$ of mother of LBW babies were illiterate whereas only $1 \%$ of control group mother was illiterate $(\mathrm{p}=$ 0.000). So, it shows that maternal education has 
Table 1. shows distribution of birth weight among LBW

\begin{tabular}{|l|l|}
\hline Birth weight (kg) & No. of newborn (\%) \\
\hline$<1$ & $3(1.44 \%)$ \\
\hline $1-1.49$ & $14(6.76 \%)$ \\
\hline $1.5-2.49$ & $190(91.78 \%)$ \\
\hline
\end{tabular}

statistically significant association with LBW. Residence of the mother also came out to have significant association with LBW ( $\mathrm{p}=0.017)$.

In LBW group 35.3\% $(\mathrm{n}=73)$ of mothers had weight $<50 \mathrm{kgs}$ in contrast to mother of NBW group in whom only $5.3 \%(\mathrm{n}=11)$ of mothers had $<50 \mathrm{~kg}(\mathrm{p}=0.000)$. So, weight of mother was found to have strong association with LBW babies. $23.7 \%$ of mothers of LBW babies were with height

Table 2. Distribution of maternal risk factors for LBW along with their statistical characteristics

\begin{tabular}{|c|c|c|c|c|}
\hline Variables & & $\begin{array}{l}\text { Cases } \\
(\%)\end{array}$ & $\begin{array}{l}\text { Control } \\
(\%)\end{array}$ & Statistic values \\
\hline Maternal age & $\begin{array}{l}<20 \\
21-25 \\
26-30 \\
31-35 \\
>35\end{array}$ & $\begin{array}{l}13(6.3) \\
48(23.2) \\
97(46.9) \\
39(18.8) \\
10(4.8)\end{array}$ & $\begin{array}{l}3(1.4) \\
28(13.5) \\
139(67.9) \\
36(17.4) \\
1(0.5)\end{array}$ & $\begin{array}{l}\mathrm{p}=0.000 \\
\mathrm{X}^{2}=26.087\end{array}$ \\
\hline Maternal education & $\begin{array}{l}\text { Illiterate } \\
\text { Primary } \\
\text { Secondary } \\
\text { Higher seconday }\end{array}$ & $\begin{array}{l}19(9.2) \\
25(12.1) \\
19(9.2) \\
144(69.6)\end{array}$ & $\begin{array}{l}2(1) \\
7(3.4) \\
17(8.2) \\
181(87.4)\end{array}$ & $\begin{array}{l}\mathrm{p}=0.000 \\
\mathrm{X}^{2}=28.210\end{array}$ \\
\hline Residence & $\begin{array}{l}\text { Urban } \\
\text { Rural }\end{array}$ & $\begin{array}{l}159(76.8) \\
48(23.2)\end{array}$ & $\begin{array}{l}70(33.8) \\
137(66.2)\end{array}$ & $\begin{array}{l}\mathrm{p}=0.017 \\
\mathrm{X}^{2}=5.737\end{array}$ \\
\hline Maternal weight & $\begin{array}{l}<50 \mathrm{~kg} \\
>50 \mathrm{~kg}\end{array}$ & $\begin{array}{l}73(35.3) \\
134(64.7)\end{array}$ & $\begin{array}{l}11(5.3) \\
196(94.7)\end{array}$ & $\begin{array}{l}\mathrm{p}=0.000 \\
\mathrm{X}^{2}=57.410\end{array}$ \\
\hline Maternal height & $\begin{array}{l}<145 \mathrm{~cm} \\
>145 \mathrm{~cm}\end{array}$ & $\begin{array}{l}49(23.7) \\
158(76.3)\end{array}$ & $\begin{array}{l}6(2.9) \\
201(97.1)\end{array}$ & $\begin{array}{l}\mathrm{p}=0.000 \\
\mathrm{X}^{2}=38.769\end{array}$ \\
\hline Weight gain during pregnancy & $\begin{array}{l}<5 \mathrm{~kg} \\
5-10 \mathrm{~kg} \\
\geq 10 \mathrm{~kg}\end{array}$ & $\begin{array}{l}50(24.2) \\
103(49.8) \\
54(26.1)\end{array}$ & $\begin{array}{l}1(0.5) \\
34(16.4) \\
172(83.1)\end{array}$ & $\begin{array}{l}\mathrm{p}=0.000 \\
\mathrm{X}^{2}=143.441\end{array}$ \\
\hline Antenatal visits & $\begin{array}{l}<3 \\
>3\end{array}$ & $\begin{array}{l}22(10.6) \\
185(89.4)\end{array}$ & $\begin{array}{l}7(3.4) \\
200(96.6)\end{array}$ & $\begin{array}{l}\mathrm{p}=0.004 \\
\mathrm{X}^{2}=8.343\end{array}$ \\
\hline Parity & $\begin{array}{l}\text { Primi } \\
\text { Multi }\end{array}$ & $\begin{array}{l}115(55.6) \\
92(44.4)\end{array}$ & $\begin{array}{l}79(38.2) \\
128(61.8)\end{array}$ & $\begin{array}{l}\mathrm{p}=0.000 \\
\mathrm{X}^{2}=12.571\end{array}$ \\
\hline Antepartum hemorrhage & $\begin{array}{l}\text { Yes } \\
\text { No }\end{array}$ & $\begin{array}{l}25(12.1) \\
182(87.9)\end{array}$ & $\begin{array}{l}4(1.9) \\
203(98.1)\end{array}$ & $\begin{array}{l}\mathrm{p}=0.000 \\
\mathrm{X}^{2}=16.352\end{array}$ \\
\hline Previous abortion & $\begin{array}{l}\text { Yes } \\
\text { No }\end{array}$ & $\begin{array}{l}46(22.2) \\
161(77.8)\end{array}$ & $\begin{array}{l}15(7.2) \\
192(92.3)\end{array}$ & $\begin{array}{l}\mathrm{p}=0.000 \\
\mathrm{X}^{2}=19.311\end{array}$ \\
\hline Previous LBW & $\begin{array}{l}\text { Yes } \\
\text { No }\end{array}$ & $\begin{array}{l}22(10.6) \\
185(89.4)\end{array}$ & $\begin{array}{l}3(1.4) \\
204(98.6)\end{array}$ & $\begin{array}{l}\mathrm{p}=0.000 \\
\mathrm{X}^{2}=15.368\end{array}$ \\
\hline Birth spacing & $\begin{array}{l}<2 \text { yrs } \\
>2 \text { yrs }\end{array}$ & $\begin{array}{l}51(24.6) \\
156(75.4)\end{array}$ & $\begin{array}{l}10(4.8) \\
197(95.2)\end{array}$ & $\begin{array}{l}\mathrm{p}=0.000 \\
\mathrm{X}^{2}=32.319\end{array}$ \\
\hline hemoglobin level (gm\%) & $\begin{array}{l}5.1-8 \\
8.1-11 \\
\geq 11\end{array}$ & $\begin{array}{l}16(7.7) \\
115(55.6) \\
76(36.7)\end{array}$ & $\begin{array}{l}0(0) \\
14(6.8) \\
192(93.2)\end{array}$ & $\begin{array}{l}\mathrm{p}=0.000 \\
\mathrm{X}^{2}=145.285\end{array}$ \\
\hline Tobacoco/alcohol & $\begin{array}{l}\text { Yes } \\
\text { No }\end{array}$ & $\begin{array}{l}13(6.3) \\
194(93.7)\end{array}$ & $\begin{array}{l}3(1.4) \\
204(98.6)\end{array}$ & $\begin{array}{l}\mathrm{p}=0.011 \\
\mathrm{X}^{2}=6.501\end{array}$ \\
\hline
\end{tabular}


less than $145 \mathrm{~cm}$ whereas only $2.9 \%$ of mothers with height less than $145 \mathrm{~cm}$ were seen in control group. By applying chi square test maternal height was found to be significantly $(\mathrm{p}=0.000)$ different among the cases and controls.

In LBW babies, maximum number of mothers had weight gain of 5 to $10 \mathrm{~kg}$ only during pregnancy whereas weight gain was higher in range (i.e. $\geq 10$ $\mathrm{kg}$ ) in control group. The difference was statistically significant with $p$ value of 0.000 . Mean total weight gain during pregnancy was $8.3 \mathrm{~kg}$ in case group and 11.7 in control group.

Similarly statistically significant association of LBW with antenatal checkup was identified in the study population $(p=0.004)$. The study showed the babies weight was influenced significantly by the number of antenatal checkups made by the mother.

Regarding obstetric history of mother presence of abortion and previous baby with LBW was found to have statistically significant association with LBW $(p=0.000)$, in current baby. Also most mothers of LBW babies were found to be primipara i.e. $55.6 \%(n=115)$ which was opposite in control group. The difference was statistically significant $(p=0.000)$. LBW was also significantly associated with birth spacing as $24.6 \%$ of LBW mothers had birth spacing $<2$ yrs whereas in control group only $4.8 \%(\mathrm{p}=0.000)$. Antepartum haemorrhage during pregnancy was seen in $12 \%(\mathrm{n}=25)$ of cases whereas only $1.9 \%(n=4)$ of control group had the problem $(p=0.000)$. This study also showed significant associating of LBW with intake of tobacco or alcohol intake $(p=0.011)$. Mean haemoglobin in mothers of LBW babies were 10.8 $\mathrm{gm} \%$ and in mothers of NBW babies were $12.1 \mathrm{gm}$ $\%$. Less haemoglobin level in mothers were found to be significantly associated with LBW ( $p=$ 0.000). Table 2 shows distribution of various variables in case and controls and its statistical evaluation.

\section{DISCUSSION}

A prospective study done in two different hospital of Pakistan showed incidence of LBW to be $9.9 \%$, and $10.04 \%$ and in Indonesia it was $10.2 \%{ }^{5}$
Similar to these studies our study also showed incidence of LBW 9.8\% which is comparable. But in other hospitals of Nepal the incidence were found slightly higher, $11.07 \%$ in Dhulikhel Hospital and $21.56 \%$ in Janakpur Hospital. In different district of Nepal as well the prevalence varied i.e. $20 \%$ in Kathmandu, $22 \%$ in Pokhara, $26 \%$ in Nepalgunj and $35 \%$ in Biratnagar. In various parts of India also incidence rate varied greatly, at Andhra Pradesh 26.8\%, in Northern India $32.3 \%$, in Uttarpradesh $40 \%$. These variations are probably due to geographical differences and differences in community.

In a study done by Yadav et al. at Janakpur Hospital the mean birth weight of LBW babies were $1.96 \pm$ $0.409 \mathrm{~kg} .{ }^{12}$ In this study the mean birth weight is $1.98 \mathrm{~kg}$ which is similar to the previous study done in Janakpur Hospital. However in study done by Anjum et al. the mean weight of LBW babies were $1.76 \mathrm{~kg}$ only.

In our study there was no significant differences among LBW and gender $(p=0.201)$. Another study done in Nepal by Singh et al also showed that the difference in $\mathrm{M}: \mathrm{F}$ ratio was insignificant statistically ( $p=0.057) .{ }^{10}$ But in India, one study by Swarnalatha et al. (Andrapradesh) had high proportion of female LBW babies $\left(\mathrm{X}^{2}=760\right.$; $p<0.00)$ and another study by Agarwal et al . (Utterpradesh) showed no significant differences among LBW and gender. ${ }^{14,16}$

This study found $47.8 \%$ preterm and $52.2 \%$ term among LBW babies. Among LBW babies, 119 babies $(57.5 \%)$ were SGA, $45.3 \%$ being symmetrical and $54.6 \%$ asymmetrical SGA. Badshah et al. study showed $41.6 \%$ preterm AGA and $17.8 \%$ preterm SGA and $40.6 \%$ were full term SGA among LBW babies. Among the total LBW $58.4 \%$ were SGA and $40.6 \%$ were AGA. $^{5}$ In another study by Anjum et al $59 \%$ of cases were preterm, ${ }^{16}$ whereas in a study done in Nepal majority of LBW were born at term $(70 \%){ }^{12}$ Agarwal et al. in his study also showed that GA $<37$ weeks was a significant determinant of LBW $(p \leq 0.0000) .{ }^{15}$ It seems that in developing countries 
majority of LBW are born at term while in industrialised countries the majority are preterm.

In a study done by Badshah et al. in Pakistan, teenage mothers were independently associated with SGA babies compared to middle age and older age with $\mathrm{p}$ value 0.01 .5 Similarly Swarnalatha et al. showed in his hospital based study that prevalence of LBW was high and significant in less than 20yrs of age mothers $\left(\mathrm{X}^{2}=11.19 ; p<0.000\right) .{ }^{13}$ In Pakistan a study by Anjum et al. also showed that teenage pregnancy was a significant risk for LBW $(p=0.007) .{ }^{16}$

Another study in India done by Agarwal et al. had maximum percentage of LBW observed in two extreme of ages i.e. $<20 \mathrm{yrs}(58.5 \%)$ and $\geq 30 \mathrm{yrs}$ (48.8\%). The difference was statistically significant $(p<0.0000) .{ }^{15}$ In a study done in janakpur zonal hospital LBW babies mostly came from mother of $<19$ and $>30$ yrs age group. ${ }^{11}$ In a study by Gagan et al. in North India also mothers aged $<18$ yrs $(42.86 \%)$ was a significant group where the percentage of LBW was more. ${ }^{15}$ Similar to these various studies our study also showed teenage and elderly mothers as significant group for LBW babies. But some other studies did not show age of mother to have statistically significant association with LBW. ${ }^{10}$

Various studies done, for example, by Badshah et al., Swarnalatha et al., Agarwal et al., Yadav et al., Anjum et al., Agrawal et al., Siramaneerat et al. all showed significant association between maternal educational level and LBW.5,9,11,13-16 But different studies also showed no association between residency and LBW. ${ }^{11,13}$ Our study showed significant association between residence of mother with LBW ( $p=0.017)$. Most deliveries in rural areas are still done at home so those population does not reach tertiary hospital hence we are unable to record them. This may be the reason for the presence of more urban population in a centrally located hospital.

There was statistical significant association of LBW with maternal weight less than $45 \mathrm{~kg}\left(\mathrm{X}^{2}=\right.$ 83.25; $p<0.000$ ) in a study by Swarnalatha et al. ${ }^{13}$ Agarwal et al. also showed significance with LBW and weight $<50 \mathrm{kgs}(p=0.000)$ as well as mother's height $<150 \mathrm{~cm}(p<0.000) .{ }^{15}$ In Pawar et al. study form Kerala maternal weight less than $60 \mathrm{~kg}$ were mentioned as a strong association factor for LBW. In Eastern Nepal a study done by Bhaskar et al. showed that maternal weight and height significantly affected the weight of babies ( $p=$ 0.001). ${ }^{17}$ In this study also maternal weight less than $50 \mathrm{kgs}$ and height less than $145 \mathrm{~cm}$ were both found to be statistically significant risk factor for LBW.

In a study done by Swarnalatha et al. at Andhra Pradesh weight gain during pregnancy less than $6 \mathrm{~kg}$ was significantly association with LBW $\left(\mathrm{X}^{2}\right.$ $=166.41 ; p<0.000) .{ }^{14}$ In another study incidence of LBW was more seen in those mothers with total weight gain $<10 \mathrm{~kg}$ during pregnancy $(p<0.001){ }^{10}$ Similar to these result our study also shows maximum number of mothers with LBW babies had weight gain of only 5-10 kg during pregnancy.

Multiple studies shows that birth weight of babies was influenced significantly by the number of antenatal checkups made by mother. ${ }^{9,10,13,15-17}$ In this study we also found statistically significant association of poor antenatal checkups with LBW $(p=0.004)$.

Two studies came with same result as primi mothers were more in proportion in LBW cases. ${ }^{18,14}$ However Agarwal et al. and Singh et al. showed no association of parity with LBW. ${ }^{10,15}$ In this study primi parity was found to have statistical significant association with LBW.

Previous preterm infant was one of the commonest factors associated with LBW seen in study done in four district surveys done in Nepal. ${ }^{12}$ In this study also we found that previous abortion as well as previous baby with LBW was statistically significant risk factors for LBW ( $p=0.000)$. But in other two studies it was insignificant factor. ${ }^{11,15}$ Other maternal factors like birth spacing and tobacco/alcohol intake was highly significant in many studies. ${ }^{13,15,16}$ But Yadav et al. showed no significant association in relation to conception interval with LBW. ${ }^{11}$ This study also showed 
significant association with birth spacing $<2$ yrs and tobacco/alcohol.

The same study by Yadav et al. showed association with antepartum haemorrhage $(p=0.04)$ as well as anaemia $(p=0.002) .{ }^{11}$ In this study also antepartum haemorrhage was seen in $12 \%$ of cases and $1.9 \%$ of controls which was statistically significant $(p=$ 0.000). Maternal anaemia was highly significant factor association for LBW in many other studies like Badshah et al., Swarnalatha et al., Agarwal et al., Singh et al., Khan et al. Here in this study also less haemoglobin level in mothers were found to be significantly association with LBW $(p=0.000) .5,10,13,15$

\section{CONCLUSIONS}

Multiple maternal factors like maternal age, maternal education, residence, maternal weight, maternal height, weight gain during pregnancy, antenatal visits, parity, antepartum haemorrhage, previous abortion, previous LBW, birth spacing, haemoglobin level and tobacoco/alcohol intake were found as significant risk factors for LBW. The study findings are not surprisingly new but it strongly demands necessity of improving maternal nutrition, education, health care services and public awareness in order to prevent delivery of LBW babies thereby helps decreasing perinatal mortality, morbidity rates of our country.

\section{ACKNOWLEDGEMENTS}

The author extends the profound sense of gratitude to the study participants and gives the highest gratitude to the neonatal unit staffs of our institute for the support during research.

To cite this article: Kayastha P, Manandhar SR. Incidence and risk factors of low birth weight among babies delivered at tertiary level teaching hospital. MJSBH. 2019;18(2):29-35.

Conflict of Interest: None declared

\section{REFERENCES}

1. Askenazi DJ, Goldstein SL. Renal conditions. In: Cloherty JP, Eichenwald EC, Stark AR, editors. Manual of neonatal care. 7th ed. Philadelphia, LWW; 2012: 350-76p.

2. Ramachandran U. A Review Of Low Birth Weight. J. Nep Med Assoc. 2000;39:377-81.

DOI:http://www.jnma.com.np/jnma/index.php/jnma/article/download/817/1534/

3. OECD (2014). Low birth weight. In Society at a Glance: Asia/Pacific; 2014.

DOI: https://doi.org/10.1787/soc_aag-2014-24-en

4. Paudel D, A. Thapa, P. R. Shedain, B. Paudel. 2013. Trends and determinants of neonatal mortality in Nepal: Further analysis of the Nepal Demographic and Health Surveys, 2001-2011. Calverton, Maryland, USA: Nepal Ministry of Health and Population, New ERA, and ICF International.

DOI: https://dhsprogram.com/pubs/pdf/FA75/FA75.pdf

5. Badshah S, Mason L, McKelvie K, Payne R, Lisboa JGP. Risk factors for low birthweight in the public-hospitals at Peshawar, NWFP-Pakistan. BMC Public Health. 2008;197(8):1-10.

DOI: https://doi.org/10.1186/1471-2458-8-197

6. WHO Global Nutrition Targets 2025:Low Birth Weight Policy Brief Available from http://www.who.int/nutrition/topics/globaltargets_lowbirthweight_policybrief.pdf, accessed on 21.07.2015

7. Nepal Demographic and health survey, 2011. Morbidity and nutrition.

Available from http://www.who.int/maternal_child_adolescent/epidemiology/profiles/neonatal_child/npl.pdf, accessed on 21.07.2015

8. Upadhyay S, Biccha RP, Sherpa MT, Shrestha R, Panta PP. Association between maternal body mass index and the birth weight of neonates. Nepal Med Coll J. 2011;13(1):42-5. 
9. Siramaneerat I, Agushybana F, Meebunmak Y. Maternal Risk Factors Associated with Low Birth Weight in Indonesia. Open Public Health J. 2018;11:376-83.

DOI: https://doi.org/10.2174/1874944501811010376

10. Iltaf G, Shahid B, Khan MJ. Incidence and associated risk factors of low birth weight babies born in Shaikh Khalifa Bin Zayad Al-Nayan Hospital Muzaffarabad, Azad Jammu and Kashmir. Pak J Med Sci. 2017;33(3):626-30. DOI: https://doi.org/10.12669/pjms.333.12413

11. Singh SD, Shrestha S, Marahatta SB. Incidence and risk factors of low birth weight babies born in Dhulikhel Hospital. JIOM. 2010;32(3):39-42.

DOI: https://doi.org/10.3126/joim.v32i3.4959

12. Yadav DK, Chaudhary U, Shrestha N. Risk Factors Associated with Low Birth Weight. J Nepal Health Res Counc. 2011;9(19):159-64.

DOI: http://www.jnhrc.com.np/index.php/jnhrc/article/view/266/264

13. MIRA. Low Birth Weight prevalence and associated factors in four regions of Nepal. (A multi- hospital based study) UNICEF. June 2000.

14. Swarnalatha1 N, Bhuvaneswari P. An epidemiological study of low birth weight in a tertiary care hospital, Tirupati, Andhra Pradesh .Int J Cur Res Rev 2013;05(16):54-62.

DOI: http://ijcrr.com/uploads/1131_pdf.pdf

15. Gagan A, Sartaj A, Kapil G, Kumar V, Parul G, Garg M, et al. Maternal Risk Factors Associated with Low Birth Weight Neonates in a Tertiary Care Hospital, Northern India. J Community Med Health Educ. 2012;2:177.

DOI: https://doi.org/10.4172/2161-0711.1000177

16. Agarwal K, Agarwal A, Agrawal VK, Agrawal P, Chaudhary V. Prevalence and determinants of "low birth weight" among institutional deliveries. Ann Nigerian Med. 2011;5(2):48-52.

DOI: https://doi.org/10.4103/0331-3131.92950

17. Anjum F, Javed T, Afzal MF, Sheikh GA. Maternal Risk Factors Associated with Low Birth Weight: A Case Control Study. Annals of KEMU. 2011;17( 3):223-8.

18. Bhaskar RK, Deo KK, Neupane U, Bhaskar SC, Yadav BK, Pokharel HP, et al. A Case Control Study on Risk Factors Associated with Low Birth Weight Babies in Eastern Nepal. International Journal of Paediatrics. 2015.1-7. DOI: https://doi.org/10.1155/2015/807373

19. Pawar A, Kumar D. Maternal factors associated with low birth weight: a case control study in rural Kerala. Int J of Community Med Public Health. 2017;4(10):3793-95. DOI: https://doi.org/10.18203/2394-6040.ijcmph20174252

20. Khan A, Nasrullah FD, Jaleel R. Frequency and risk factors of low birth weight in term pregnancy. Pak J Med Sci. 2016;32(1):138-42.

DOI: https://doi.org/10.12669/pjms.321.8120 